\title{
Tomoi (Muay Thai Kickboxing) death: A lesson learned
}

\author{
Rashidi Ahmad, Nasir Mohamad, Terence Leslie Silva \\ Minsyeh, Nik Ariff Nik Mohamed
}

\begin{abstract}
Introduction: Tomoi also known as Muay Thai kickboxing is referred to as "The Science of Eight Limbs". Deaths do occur, however, sprained fingers and toes, cuts and bruises on the head, face and neck and bloody noses are the more typical injuries. Case Report: We report a case of Tomoi kick boxer who sustained severe traumatic brain injury in the ring during an inaugural Tomoi kickboxing competition in northeastern Kelantan. Conclusion: This was the first time such a case had been reported in Malaysia. Health and safety measures to avoid such injury are also recommended.
\end{abstract}

Rashidi Ahmad' ${ }^{1}$ Nasir Mohamad ${ }^{2}$, Terence Leslie Silva ${ }^{3}$, Minsyeh $^{4}$, Nik Ariff Nik Mohamed ${ }^{5}$

Affiliations: ${ }^{1}$ Associate Professor - Senior Lecture/ Emergency Physician, Department of Emergency Medicine, School of Medical Sciences, Health Campus USM, 16150 Kubang Kerian, Kelantan, Malaysia; ${ }^{2}$ Nasir Mohamad. Senior Lecturer/ Emergency Physician, Department of Emergency Medicine, School of Medical Sciences, 16150 Kubang Kerian, Kelantan, Malaysia; ${ }^{3}$ Registrar, Department of Emergency Medicine, School of Medical Sciences, Health Campus USM, 16150 Kubang Kerian, Kelantan, Malaysia; ${ }^{4}$ Registrar, Department of Radiology, School of Medical Sciences, Health Campus USM, 16150 Kubang Kerian, Kelantan, Malaysia; ${ }^{5}$ Senior Lecturer/ Emergency Physician, Department of Emergency Medicine, School of Medical Sciences, 16150 Kubang Kerian, Kelantan.

Corresponding Author: Nasir Mohamad, Department of Emergency Medicine, School of Medical Sciences, Kubang Kerian, Kota Bharu, Kelantan, Malaysia - 16150; Phone: +6097676978; Fax: +6097673219; Email: drnasirmohamadkb@yahoo.com

Received: 14 September 2010

Accepted: 14 October 2010

Published: 15 November 2010
Keywords: Tomoi death, Preventable, Health and safety measures

$$
* * * * * * * * *
$$

Ahmad R, Mohamad N, Silva TL, Minsyeh, Mohamed NAN. Tomoi (Muay Thai Kickboxing) death: A lesson learned. International Journal of Case Reports and Images 2010;1(3):10-14.

$$
* * * * * * * * * \text {. }
$$

doi:10.5348/ijcri-2010-11-6-CR-3

\section{INTRODUCTION}

Tomoi is a Malaysian name for the South-East Asian martial art known as Muay Thai in Thailand, Pradal Serey in Cambodia and Lethwei in Myanmar. Tomoi refers to siku lutut, which in Malay is translated literally as "elbows knees" [1]. It is not known exactly when Tomoi was first practiced but it is most widely practiced in northern Malaysia along the Thai border. It remained a favorite game until 1990 when the Kelantan government banned a number of traditional arts including Malay attires, dances and along with them Tomoi. In late 2006, the ban was abolished and the art was allowed to be practiced again under the proposed name of "Muay Kelate" [1]. The preferred name which is used by its promoters, refers to freestyle kickboxing, while those outside the state of Kelantan often just call the sport Muay Thai.

We present a case of an amateur Tomoi kick boxer who sustained severe traumatic brain injury in the ring during a fight. As this was our first experience encountering such a case in the accident and emergency room setting, we recommend a few measures to ensure this deadly sport to be safe and we hope that fatal injuries can be avoided in the future. 


\section{CASE REPORT}

A 20-year-old Siamese male was rushed into the Emergency Department of Hospital Universiti Sains Malaysia (HUSM), Health Campus, after passing out during a kickboxing bout. According to the witnesses, he was previously healthy and not known to have any medical and surgical illness. During the event his opponent elbowed him on his head and kneed him at the right side of his neck. He tried to continue the match but soon he complained of giddiness and rapidly lost consciousness. After two hours efforts to revive him by the ringside failed, he was brought to the Emergency Department of HUSM. There was no medical team standing by during this inaugural amateur competition of Muay Kelate.

Primary assessment upon arrival revealed that the fighter was unconscious with a Glasgow Coma Scale (GCS) of 4/15 (E1V1M2). Both pupils were dilated and showed sluggish response to light. His respiratory pattern and vital signs were normal. A $5 \mathrm{x}$ $5 \mathrm{~cm}$ hematoma was noted at the right side of neck. $\mathrm{He}$ was then intubated for airway protection and cerebral resuscitation. Two hundred $\mathrm{mL}$ of $20 \%$ mannitol was administered intravenously for 20 minute to reduce intracranial pressure. The Computed Tomography scan (CT scan) of the brain revealed an acute subdural hematoma at right frontotemporal region, supratentorial subarachnoid hemorrhage and massive cerebral edema with a significant midline shift (Figures 1, 2). The patient was subsequently managed by the neurosurgical team. An intracranial pressure catheter was inserted into the left lateral ventricle under local anesthesia and it revealed an elevated intracranial pressure of $60 \mathrm{mmH}_{2} \mathrm{O}$. His condition deteriorated further after the procedure. He developed hypotension and bradycardia. Intravenous dopamine and noradrenaline were administered to support the blood pressure. Finally he succumbed 24 hours afterwards. The cause of death was attributed by severe traumatic brain injury.

\section{DISCUSSION}

Tomoi or muay thai kick boxing is a form of martial art. Most people perceive that martial arts are safe with little thought given to the physical forces involved. Some enthusiasts are attracted to the martial arts to learn self-defense whereas others participate to improve physical fitness, flexibility, and some even for self-esteem. A fraction of others join purposely for financial reasons and even for the glory.

Tomoi is referred to as "The Science of Eight Limbs" since it allows the use of punches or fists, kicks, knees, and elbows. A master practitioner of Tomoi has the ability to execute strikes using eight "points of contact" as opposed to "two points" (fists) in Western boxing and "four points" (fists, feet) used

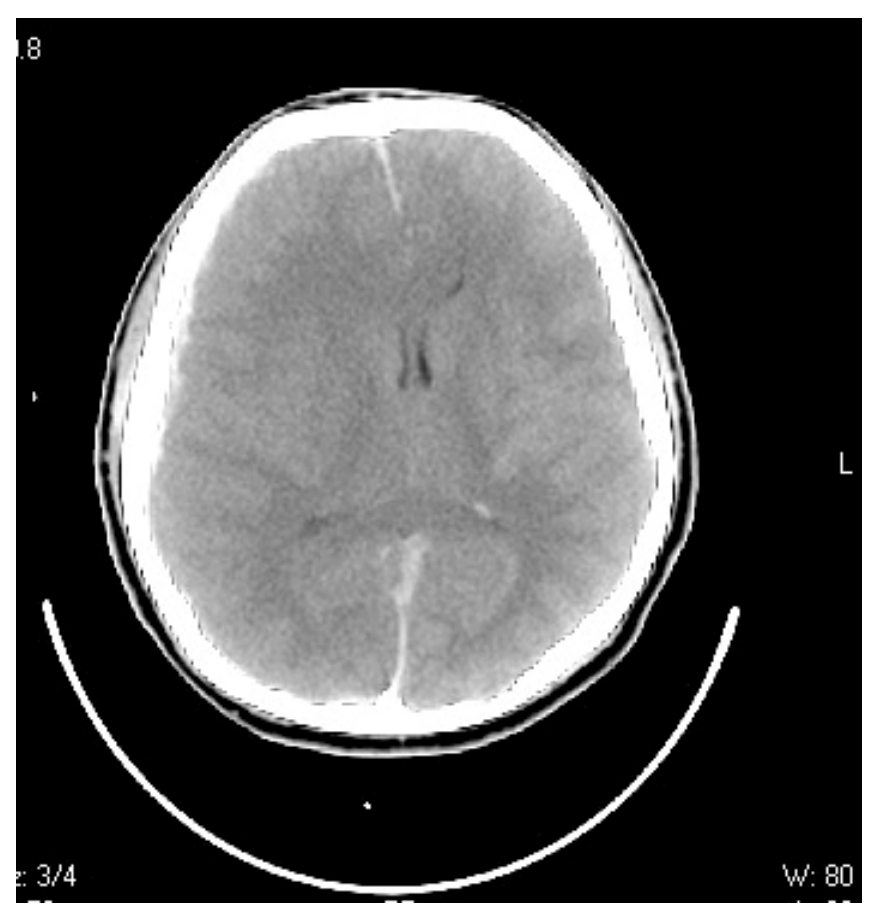

Figure 1: CT scan of the brain showing right fronto-temporal hematoma and cerebral edema with midline shift

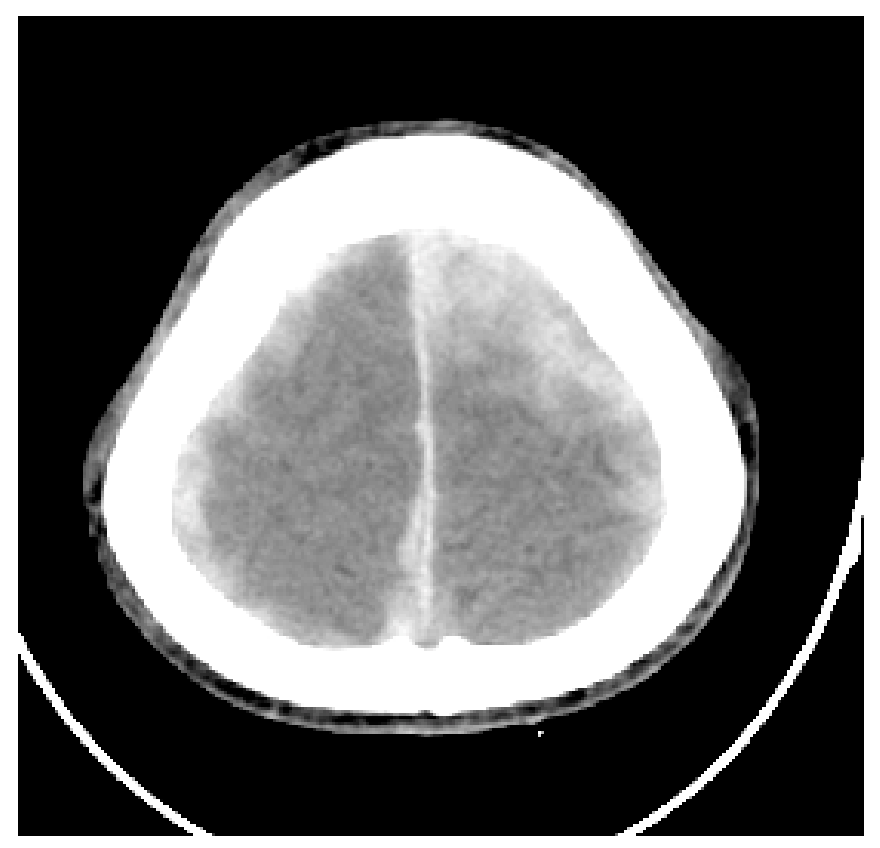

Figure 2: CT scan of the brain showing interhemispheric hemorrhage and subarachnoid hemorrhage

in the primarily sport-oriented forms of martial arts [1]. Tomoi also involves two mode of action which in the attack and defense position. In attack position the fighter is allowed to use punching, elbowing, kicking and knee. Since a higher score with possibly early knockout is obtained with strike to the head, all 
fighters aim their ultimate attack towards head region $[1,2]$. In Tomoi they can get points when they land clean kicks and knees to the body, head or neck with good technique regardless of the effect they have on the opponent. By contrast punches, low kicks and elbows must have a physical effect on the opponent or cause them to show they are hurt in order to score [3].

The defense modes are categorized into 6 groups which include blocking, redirection, avoidance, evasion, disruption and anticipation. The fighters stop strike by blocking, like the shin block, to prevent reaching its targert. Low and mid-body roundhouse kicks are normally blocked with the upper portion of a raised shin. High-body strikes are blocked with the forearm, glove, elbow or shin. Mid-section roundhouse kicks can also be caught/trapped, allowing for a sweep or counter attack to the remaining leg of the opponent. Punches are blocked with an ordinary boxing guard and techniques similar, if not identical, to basic boxing technique. A common measure of blocking a punch is using the hand on the same side as the oncoming punch. Sometimes they also move body part out of attack range simply to avoid the strike. In the hard way, fighters also anticipate the attack by using its attack position as a defense mechanism like using low kick to counterattack high angle kick [1-3].

In amateur boxing competition the main objective is to score maximum points and the knockout or knockdown is a byproduct, whereas, in professional boxing knockout and/or knockdown is an objective [4]. A competitor seeks victory by various methods but commonly by concussing an opponent into defenselessness through blunt head trauma, disabling an opponent through joint subluxation, dislocation, or soft tissue trauma, causing syncope by way of a neck choke or even by coercing an opponent into submission by any permutation of the above [5]

Tomoi combat permit a fighter to attack any body parts excepts the groin. The attack of fighter on their opponent may cause injury in various part of the body. Injury is classified as blunt trauma injury. Among the blunt trauma injuries, head injuries are the most dangerous which during the game can cause intracranial bleeding lead to death. Schwartz and colleagues found that the forces of punches and kicks to the viscoelastic dummy head is violent enough to engender encephalopathy [6]. Blunt trauma and mechanical overload of the musculoskeletal system are common sources of morbidity among Tomoi fighters. Associated injuries include contusions and hematoma formation, sprains, strains and fractures. The lower extremities are at particular risk for injury as they are used extensively in most kickboxing styles to both defend against and deliver full-force attacks $[6,7]$. Unbalancing an opponent with kick or throwing action (usually they attack at lower extreemities) and immediately following with a strong striking technique is a very effective way to persuade juries to give a better score.
Gartland et. al. showed that Tomoi kickboxing had an injury rate of between 2 to 14 per 1,000 participants per year. The rate was similar to the injury rates in other combative martial arts such as taekwondo and karate [2, 8-10]. Deaths do occur in Tomoi [11], however, as in boxing, soft tissue injuries such as sprained fingers and toes, cuts and bruises on the head, face, and neck and traumatic epistaxis have been shown to be the most common type of injury, contributing to at least $80-90 \%$ of all injuries. Sprain and strain were the second most common type of injury in beginners and amateurs. On the contrary, in professional fighters, fractures are the second most commonly reported injuries and the most common sites were the nose, carpal bones, metacarpals, digits, and ribs [12]. This is perhaps not surprising as the forces involved are a lot higher, less protective equipment is used, and subjects are likely to train harder. Boxing can cause subdural hematoma [13, 14]. A properly located strike to the head (or a series of less accurate blows) can cause tearing to the bridging veins that connect the brain and the sinuses that carry blood away from the brain [14, 15]. This condition is thought to be the most common cause of fatalities in competitive boxing and is a risk in other contact sports [16]. Our patient died because of severe traumatic brain injury instead of carotid injury as the CT scan of brain did not show subarachnoid hemorrhage involving the posterior circulation.

Few steps could be taken to avoid such injuries [4]. From the medical point of view, we suggest all fighters should have a complete medical examination including an ophthalmic evaluation, resting electrocardiography or even echocardiogram and certain laboratory investigations such as platelet count, bleeding time and coagulation profile prior to obtaining a fighting license. In extreme situation, cerebral angiography may be required to rule out arteriovenous malformation or cerebral aneurysm. The results should be documented in the fighter's record book. Kick boxer should not be allowed to compete at any tournament without producing his/her record book.

This documentation should include pre-match medical investigation and post-match injury. It should be completed in the context that it may be used for follow-up medical care which is very important, potential legal proceedings, or possibly as data for future research [17]. Likewise, an informed consent statement can be used which each competitor acknowledges and signs. The statement in the form may address the risks of participation and limitations of ringside medical care, as well as the possibility that data collected could be used for future research. Contact information of competitors may also prove beneficial should follow up be necessary [17].

During a bout the attending Medical Officer should have the authority to stop the bout for medical reasons. In the case of a knockout, the doctor should perform a thorough medical examination and subsequently be allowed to determine the need of 
further medical observation and/or hospital admission should. Throughout the competition, it should be made mandatory that an on-site emergency medical team is available $[18,19]$. The injured patient, therefore, can be rapidly resuscitated and stabilized by the trained medical team prior to the transfer to the nearest trauma centre for immediate treatment.

Another important issue for medical personnel is that they need to integrate themselves as soon as possible in the event planning process. They can be consultants to the promoter and will be the competitors' on-scene care providers. One should not assume that the promoter will address the details of medical support. Finally, details about the rules and protective equipment to be used are important in planning for types of injuries expected [17].

It is still debatable whether headgears really diminish the impact of a blow since it increases the shearing injury to nerve fibers and neurons in the brain in proportion to the degree of acceleration to the head but it is indisputable that since their mandatory use in amateur boxing, the rate of facial injuries has dramatically diminished [20]. We, however, strongly recommend that organizers/promoter compel all fighters to use protective elbow/shin pads in order to reduce the impact on the head and neck regions. Though these may not reduce the incidences of the injuries involved in this aggressive contact sport, we certainly hope to reduce the severity of the injuries that these brave fighters sustain.

\section{CONCLUSION}

Tomoi is similar to other kickboxing sport that should be guided with safety measures in order to prevent its high morbidity and mortality related injuries. Both fighters and promoters should communicate to each other for early detection of life threatening signs and symptoms related injury. Last but not least, the sports organizations must implement strict safety guidelines for all fighters prior to the contest.

\section{$* * * * * * * * *$}

\section{Acknowledgement}

I would like to thank Dean, School of Medical Sciences, USM, Malaysia, for his support.

\section{Author Contributions}

Rashidi Ahmad - Conception and design, Acquisition of data, Analysis and interpretation of data, Critical revision of the article, Final approval of the version to be published

Nasir Mohamad - Conception and design Analysis and interpretation of data, Drafting the article, Critical revision of the article, Final approval of the version to be published

Terence Leslie Silva - Acquisition of data, Drafting the article, Final approval of the version to be published Minsyeh - Acquisition of data, Drafting the article, Final approval of the version to be published

Nik Ariff Nik Mohamed - Acquisition of data, Drafting the article, Final approval of the version to be published

\section{Guarantor}

The corresponding author is the guarantor of submission.

\section{Conflict of Interest}

Authors declare no conflict of interest.

\section{Copyright}

(C) Rashidi Ahmad et. al. 2010; This article is distributed under the terms of Creative Commons attribution 3.0 License which permits unrestricted use, distribution and reproduction in any means provided the original authors and original publisher are properly credited. (Please see www.ijcasereportsandimages.com/copyrightpolicy.php for more information.)

\section{REFERENCES}

1. Wikipedia. Tomoi. [cited 2010 April 21]; Available from: http://en.wikipedia.org/wiki/Tomoi.

2. Ip AKK, Chan RHF. A review of Muay Thai boxing and combat sport injuries. Hong Kong Practicioner 2007; 29:242-247.

3. Myers T. How to score a Muay Thai fight. In: Muay Thai Phuket Magazine 2009; Phuket design:1-4.

4. Jako P. Safety measures in amateur boxing. British Journal of Sports Medicine 2002;36: 394-395.

5. Buse GJ. No holds barred sport fighting: a 10 year review of mixed martial arts competition. British Journal of Sports Medicine 2006;40:169-172.

6. Schwartz ML, Hudson AR, Fernie GR, Hayashi K, Coleclough AA. Biomechanical study of full-contact karate contrasted with boxing. J Neurosurg 1986;64:248-252.

7. Buse GJ, Wood RM. Safety profile of amateur kickboxing among military and civilian competitors. Mil Med 2006;171:443-447.

8. Gartland S, Malik MHA, Lovell ME. Injury and injury rates in Muay Thai kick boxing. British Journal of Sports Medicine 2001;35:308-313.

9. Zazryn TR, Finch CF, McCrory P. A 16 year study of injuries to professional kickboxers in the state of Victoria. Australia. British Journal of Sports Medicine 2003;37: 448-451.

10. Porter M, O'Brien M. Incidence and severity of injuries resulting from amateur boxing in Ireland. Clin J Sport Med 1996;6:97-101. 
11. Oler M, Tomson W, Pepe H, Yoon D, Branoff R, Branch J. Morbidity and mortality in the martial arts: a warning. J Trauma 1991;31:251-253.

12. Gartland S, Malik MHA, Lovell ME. A prospective study of injuries sustained during competitive Muay Thai kickboxing. Clin J Sport Med 2005;15:34-36.

13. Putnam P. Going-going-gone. In: Sports Illustrated, 1983;6:23-46.

14. Lampert PW, Hardman JM. Morphological changes in brains of boxers. JAMA 1984;251:26762679.

15. Cantu RC. Return to play guidelines after head injury. Clin J Sport Med 1998;17:45-60.

16. Lindsay KW, McLatchie G, Jennett B. Serious head injury in sport. Br Med J 1980;281:789-791.

17. Buse GJ. Kickboxing. In: Kordi R, Maffulli N, Wroble RR, Wallace WA, editors. Combat Sports Medicine. London:Springer; 2009. p. 331-350.

18. DeLorenzo RA. Mass gathering medicine: a review. Prehosp Disaster Med 1997;12:68-72.

19. Parrillo SJ. Medical care at mass gatherings: considerations for physician involvement. Prehosp Disaster Med 1995;10:273-275.

20. Wilkerson LA. Martial arts injuries. Journal of the American Osteopathic Association 1997;97:221227. 